\title{
Morphology in Phonology. Introduction
}

\section{Maria-Rosa Lloret}

Universitat de Barcelona. Departament de Filologia Catalana Gran Via de les Corts Catalanes, 585. 08007 Barcelona (Spain) mrosa.1loret@ub.edu

\section{Jesús Jiménez}

Universitat de València. Departament de Filologia Catalana Av. Blasco Ibáñez, 32. 46010 València (Spain) jesus.jimenez@uv.es

This fourth volume of Catalan Journal of Linguistics is devoted to a topic discussed at length in the literature but which nevertheless remains a challenge for any view of phonology: the morphology-phonology interaction. The papers collected address two related issues, the role of morphological information in phonology and the role of phonological information in morphology. The first six articles (i.e. McCarthy, Wheeler, Downing, van Oostendorp, José and Auger, and Rice) deal with the former topic; the last three (i.e. Bertinetto and Jetchev, Pérez Saldanya and Vallès, and Viaplana), with the latter. Several papers (Wheeler, van Oostendorp, Rice, Bertinetto and Jetchev, Pérez Saldanya and Vallès, and Viaplana) further discuss the role and concept of paradigms, an old Neogrammarian notion to which renewed attention has been payed both from the phonological perspective (cf. work by Benua 1995, 1997; Burzio 1994 and subsequent work; Kenstowicz 1996, 2002; Steriade 2000, and the articles in the recent volume edited by Downing et al. 2005, among others) and from the morphological perspective (cf. work by Aronoff 1994; Bauer 1997, 2001; Carstairs-McCarthy 1994, 1998; Stump 1991, 1997; van Marle 1985, 1994; Wurzel 1989, and several articles in the recent volume edited by Boucher 2002, among others). ${ }^{1}$

The first six papers are framed within Optimality Theory (OT, henceforth) and discuss the role of morphophonemics in learning (McCarthy), different ways of analyzing morphophonemic alternations (Wheeler), and the symmetries and asymmetries between phonological and morphological structure (Downing, van Oostendorp, José and Auger, and Rice).

John J. McCarthy's paper, «Taking a Free Ride in Morphophonemic Learning», pursues the idea that learners simultaneously consider various possibilities for the

1. We would like to thank all the contributors for their willingness to collaborate in this issue as well as the reviewers for the helpful comments they provided on the papers. This introduction has benefited from insights from Eulàlia Bonet, Laura Downing, and Joan Mascaró. Our work has been supported by the Ministerio de Educación y Ciencia and the FEDER (research projects HUM200401504/FILO and BFF2003-06590) and by the Generalitat de Catalunya (research groups 2005SGR01046 and 2001SGR00150). 
underlying representations corresponding to morphophonemic alternations, on the basis of both input-to-output mappings and output-to-input mappings. Learners, however, end up preferring the most restrictive grammar on the basis of the r-measure (Prince and Tesar 2004). The cases examined address alternation data that show that some $[\mathrm{B}] \mathrm{s}$ derive from $/ \mathrm{A} / \mathrm{s}$, and others from existing non-alternating $[\mathrm{B}] \mathrm{s}$. The claim is that the $[\mathrm{B}] \rightarrow / \mathrm{A} /$ information propagates back to the lexicon for non-alternating $[\mathrm{B}] \mathrm{s}$. Under this view, the learner considers lexicons in which nonalternating [B]s are and are not derived from /A/s; if a more restrictive grammar can be found, then this is chosen. An important issue that this work addresses is the way of incorporating non-existing data in the learning procedure. Since the learner is not exposed to non-existing data, what does (s)he really apprehend from these? The Free Ride Learning Algorithm (FRLA) automatically considers all possible grammars to account for a set of data and thus must entertain the possibility of the existence of a grammar that generates non-existing forms that do not contradict the phonotactics of the language. But why should the learner pursue this line of learning? The FRLA evaluates the complexity of such a grammar, which will only be chosen if it is more restrictive than the grammar generated by the common learning procedure (i.e. the one exclusively based on the input-to-output mappings or Biased Multirecursive Constraint Demotion, BMCD; cf. Prince and Tesar 2004).

Max W. Wheeler's paper, «Cluster Reduction: Deletion or Coalescence?», explores another facet of the richness of OT, here with regard to different possible interpretations of one and the same phonological phenomenon. The paper defends the idea that, although the theory might seem too rich at first sight, it contains internal mechanisms, related to the coherence of specific grammars in this case, to restrict it. The cases examined involve cluster reduction apprehended from morphophonemic alternations in Navajo and Catalan, the two languages used for exemplification. In Navajo, cluster reduction is analyzed in terms of deletion, while in the Catalan variety under investigation (i.e. the one spoken in Ibiza) it is accounted for in terms of coalescence. A consequence of this approach is the fact that certain coalescences completely eliminate the properties (i.e. the features) of one of the coalesced segments, as in the coalesced interpretation of the preconsonantal output [por ${ }_{1,2} \mathrm{~s}_{3}$ ] 'pigs', from an input $/ \mathrm{por}_{1} \mathrm{k}_{2}+\mathrm{z}_{3}$ / and a base ['por $\mathrm{k}_{2}$ ], from $/ \mathrm{por}_{1} \mathrm{k}_{2} /$, in Ibiza Catalan. An issue that is worth exploring is the possibility that, if in a given language there were no evidence in favor of one or the other interpretation, the $r$ measure could choose the best grammar on the basis of restrictiveness.

Laura J. Downing's paper, «Morphological Complexity and Prosodic Minimality», analyzes reduplication in Axininca Campa in terms of morphological minimality requirements, as opposed to previous approaches that analyze it in terms of prosodic minimality requirements (cf. McCarthy and Prince 1993, 1995). Her analysis, which further includes data from Dijari, suggestively emphasizes the correlation between prominent/complex morphological structures (roots over affixes, with roots being bimorphemic, for instance) and complex prosodic structures (bimoraic or bisyllabic structures), along the lines already suggested by Dresher and van der Hulst (1998). The isomorphism between the morphological level and 
the prosodic/phonological level is also highlighted, on the basis of different facts, in the papers by van Oostendorp and by José and Auger.

Marc van Oostendorp's paper, «Expressing Inflection Tonally», analyzes the tonal alternations in the adjectival inflection of Limburg Dutch as a difference in underlying representations, arguing against previous analyses that relate these facts to paradigmatic effects (cf. Alderete 1999). The analysis resorts to structural differences encoded in the underlying representations, in terms of floating and nonfloating moras, to distinguish the different phonological behavior of the neuter and the feminine morphemes, both of which seem to be empty at first sight. The interpretation of superficially empty positions as derived from two different underlying structures requires some level of abstraction, which the author justifies by the OT assumption of Richness of the Base (ROTB), according to which there are no language-particular restrictions on the input. Although the derivation of phonological effects by the use of empty elements is quite controversial, the paper provides interesting further evidence for the isomorphism between prominent morphological elements and prominent phonological properties. Here, more prominent morphological elements (i.e. lexical words and words with more marked morphemes, like the feminine and the masculine) are assigned a marked tone, in contrast with less prominent morphological elements (i.e. functional words and less marked morphemes like the neuter), which are assigned no tone.

Brian José and Julie Auger's paper, «Geminates and Picard Pronominal Clitic Allomorphy», analyzes the complex system of pronominal clitics in Vimeu Picard. As in van Oostendorp's work, the analysis they propose derives from underlying structural differences and involves the existence of floating and non-floating elements. In van Oostendorp's work the difference is accounted for with different underlying representations of superficially empty positions. In José and Auger's work the difference is accounted for with different underlying representations of surface geminate consonants. Here, surface geminate consonants are derived from singletons (e.g. $/ \mathrm{m} /$ for the first-person singular clitic); from two-root geminates, with both roots linked (e.g. /11/ for the third-person singular clitic) or with one root floating (e.g. $/ \mathrm{n}^{\mathrm{n}} /$ for the partitive/genitive clitic), and from two different singletons (e.g. /lz/ for the third-person plural clitic). As in the two previously mentioned articles (i.e. Downing's and van Oostendorp's), the isomorphism between the morphological level and the prosodic/phonological level emerges and more prominent morphological elements are assigned more prominent phonological positions or features, to satisfy the constraint MAX(RoOT)/STRESS. Two further issues are raised by this work. First, the use of the controversial notion «appendix» to justify the presence of certain clusters. The authors sometimes refer to the proper or improper syllabification of these clusters, but appendices are extrasyllabic and thus they are not presumably affected by syllabification requirements. Second, the use of Sympathy Theory for an interesting case of opacity in Vimeu Picard.

Curt Rice's paper, «Optimal Gaps in Optimal Paradigms», deals with situations in which there is no output for a given input as an effect of phonological markedness, giving rise to smaller, incomplete paradigms. In such cases one way to express the intended content of the cell in the paradigm is to turn to morpholo- 
gy and use another form of the paradigm; another way is to turn to syntax and use an alternative expression. The paper mainly focuses on the second case and draws examples from Norwegian and Hungarian verbal inflection. The analysis is framed within the Optimal Paradigms model (McCarthy 2001) and emphasizes the benefits of this view with respect to earlier treatments of absolute ungrammaticality, such as the null parse hypothesis of Prince and Smolensky (1993) and the theory of control proposed in Orgun and Sprouse (1999). An interesting issue that marginally arises during the discussion is the fact that, under the pressure of phonological markedness, morphological faithfulness (expressed in terms of MAX \{MoRPHOLOGICALCATEGORY\} constraints) can be violated and forms with more marked morphemes are replaced by forms with unmarked or less marked morphemes (imperatives replaced by infinitives, in the Norwegian case; cf. Rice 2003). Under this view, in order to maintain the isomorphism between phonology and morphology, faithfulness situations that apparently demand the ranking of the faithfulness constraints that refer to less marked morphemes over the ones that refer to more marked morphemes should result from the high ranking of other constraints.

A final note concerning this OT group of papers is in order here. Several of these papers make use of different morphological faithfulness constraints, in terms of RealizeMorpheme (e.g. van Oostendorp), in terms of Max (e.g. Rice's MaX $\{1 \mathrm{Sg}\}, \operatorname{Max}\{$ IMPERATIVE $\}, \operatorname{MAX}\{$ POTENTIAL $\}$ ), or in terms of both (e.g. José and Auger's simultaneous use of MAX(RoOT) and REALIZEMoRPHEME). It remains to be investigated what the exact scope is of these two types of constraints (REALIzE vs. MAX; cf. Kurisu 2001) and what morphological categories they can embrace. This issue further relates to the notion of paradigms used in some of these articles (Wheeler, van Oostendorp, and Rice) as well as in the next three papers. Over all, this kind of approach suggests the need for a clearer OT theory of morphology.

The last three papers of the volume are concerned with the organization of words according to the phonological characteristics they share. They deal with the lexical accessibility of words depending on their opaque or transparent relation (Bertinetto and Jetchev) and the paradigmatic classes that can be established according to the phonological patterns that the words share (Pérez Saldanya and Vallès, and Viaplana).

Pier Marco Bertinetto and Georgi Jetchev's paper, «Lexical Access in Bulgarian: Nouns and Adjectives with and without Floating Vowels», describes a psycholinguistic experiment conducted to investigate if morphologically related words with transparent (i.e. without alternations) and opaque (i.e. with alternations) morphology are equally accessed by speakers. The data are drawn from Bulgarian and are instances of a morphophonemic vowel/zero alternation that this language displays. The results show that words with transparent morphology are accessed more directly than the ones with opaque morphology. The authors conclude that while the former are rule-generated, the latter are lexically stored, i.e. directly listed in the lexicon. Interestingly enough, they did not find any significant difference between inflected and derived related forms, while other phonological properties (such as stress) might influence the time of response. The paper finally presents a brief dis- 
cussion of Italian words with and without palatalization, which are reported to have no difference in time accessibility in Celata and Bertinetto (forthcoming). Bertinetto and Jetchev suggest that the specific phonological shape of Italian inflected words (most of which end in a vowel) vs. that of Bulgarian words used in the present study (all of which end in a consonant) might be responsible for these apparently contradictory results, and they foresee further experiments.

Manuel Pérez Saldanya and Teresa Vallès' paper, «Catalan Morphology and Low-level Patterns in a Network Model», shows the importance of morphological patterns to explain the spread of certain subregularities in a language, along the lines of Cognitive Morphology and the network approach proposed by Langacker (1988) and Bybee (2001 and previous work). Examples are taken from the inflectional and derivational morphology of Catalan: inflectional examples deal with the diffusion of a velar affix in verbal conjugation; derivational examples, with the use of the prefix radio- in old and new words. The approach is interesting insofar as it is able to explain the spread of minor patterns over the general patterns in unrelated inflectional and derivational processes, an issue that is not well accounted for in alternative approaches. However, given the fact that, under this view, any subpattern is able to create its own network, it seems difficult to restrict the number of possible networks. One must acknowledge, though, that the role of (general and minor) patterns has turned out to be crucial in experimental studies (cf., among others, Langman and Bayley 2002 and also Bertinetto and Jetchev in this volume). Future work should reveal at which point the perceptual salience of these patterns calls for their recognition as units, or even as primitives, of linguistic analysis.

Finally, Joaquim Viaplana's paper, «Velar Verbs and Verbal Classes in Catalan», further discusses the issue of the spread of the velar affix in the verbal morphology of Catalan. The new contribution here is the use of a significant body of dialectal data, taken from a recently collected spoken corpus, to support the proposal that velarized verbs are organized in subpatterns and constitute different regular subclasses. The analysis is appealing given that in the alternative approach this velar segment is analyzed as part of the root, and not as part of the inflection (cf. Mascaró 1985, Wheeler 2002, among others). Viaplana argues that under the root view all these verbs are considered irregular, and it is thus difficult to justify why the «irregular» pattern should take over the «regular» non-velarized pattern in certain dialects. Over all, we again face the fact that patterns and subpatterns play an important role in phonology and morphology despite the difficulties of formalizing, limiting, and incorporating these units in linguistic analysis.

To sum up, the contributions to this volume raise many interesting questions concerning morphophonemics from different points of view. In the articles some answers to these questions are suggested. One is the search for a more restrictive and coherent grammar to account for alternations. Another one is the existence of certain symmetries between the morphological and the prosodic/phonological level. Yet another one is the role of paradigms and subparadigms (patterns and subpatterns) in phonology and morphology. Unavoidably many other questions remain unresolved and have to be left for future research: What are the consequences of Freedom of Analysis and of Richness of the Base in OT? How can we integrate and limit 
paradigms and subparadigms in a particular linguistic analysis? Hopefully, this volume sets out further paths to explore.

\section{References}

Alderete, John (1999). Morphologically Governed Accent in Optimality Theory. University of Massachusetts, Amherst, doctoral dissertation.

Aronoff, Mark (1994). Morphology by Itself. Cambridge, MA: MIT Press.

Bauer, Laurie (1997). «Derivational Paradigms». In: Booij, Geert; van Marle, Jaap (eds.). Yearbook of Morphology, 1996. Dordrecht: Kluwer, pp. 243-256.

Bauer, Laurie (2001). Morphological Productivity. Cambridge: Cambridge University Press.

Benua, Laura (1995). «Identity Effects in Morphological Truncation». In: Beckman, Jill; Walsh Dickey, Laura; Urbanczyk, Suzanne (eds.). University of Massachusetts Occasional Papers in Linguistics 18: Papers in Optimality Theory. Amherst, MA: Graduate Linguistic Student Association, pp. 77-136.

Benua, Laura (1997). Transderivational Identity: Phonological Relations between Words. University of Massachusetts, Amherst, doctoral dissertation. [Published as Phonological Relations between Words in 2000 by Garland.]

Boucher, Paul (ed.) (2002). Many Morphologies. Somerville, MA: Cascadilla Press. Bybee, Joan L. (2001). Phonology and Language Use. Cambridge: Cambridge University Press.

Burzio, Luigi (1994). Principles of English Stress. Cambridge: Cambridge University Press.

Carstairs-McCarthy, Andrew (1994). «Inflection Classes, Gender, and the Principle of Contrast». Language 70: 737-788.

Carstairs-McCarthy, Andrew (1998). «Paradigmatic Structure: Inflectional Paradigms and Morphological Classes». In: Spencer, Andrew; Zwicky, Arnold M. (eds.). The Handbook of Morphology. Oxford \& Malden, MA: Blackwell, pp. 322-334.

Celata, Chiara; Bertinetto, Pier Marco (forthcoming). «Lexical Access in Italian: Words with and without Palatalization». Lingue e Linguaggio 2/2005.

Downing, Laura J.; Hall, T. Alan; Raffelsiefen, Renate (eds.) (2005). Paradigms in Phonological Theory. Oxford: Oxford University Press.

Dresher, B. Elan; van der Hulst, Harry (1998). «Head-dependent Asymmetries in Phonology: Complexity and Visibility». Phonology 15: 317-352.

Kenstowicz, Michael (1996). «Base-Identity and Uniform Exponence: Alternatives to Cyclicity». In: Durand, Jacques; Laks, Bernard (eds.). Current Trends in Phonology: Models and Methods. Paris-X \& Salford: European Studies Research Studies \& University of Salford Press, pp. 363-393.

Kenstowicz, Michael (2002). «Paradigmatic Uniformity and Contrast». In: Csirmaz, Anikó; Li, Zhiqiang; Nevins, Andrew; Vaysman, Olga; Wagner, Michael (eds.). MIT Working Papers in Linguistics 42: Phonological Answers (and their Corresponding Questions). Cambridge, MA: MITWPL, pp. 141-163.

Kurisu, Kazutaka (2001). The Phonology of Morpheme Realization. University of California, Santa Cruz, doctoral dissertation. [Available on Rutgers Optimality Archive \#490, http://roa.rutgers.edu/.] 
Langacker, Roland W. (1988). «A Usage-Based Model». In: Rudzka-Ostyn, Brygida (ed.). Topics in Cognitive Linguistics. Amsterdam \& Philadelphia: John Benjamins, pp. 127-161. [Revised version published in Langacker, Roland W. (ed.) (1990). Concept, Image, and Symbol: The Cognitive Basis of Grammar. Berlin: Mouton de Gruyter, pp. 261-288.]

Langman, Juliet; Bayley, Robert (2002). «The Acquisition of Verbal Morphology by Chinese Learners of Hungarian». Language Variation and Change 14: 55-77.

Mascaró, Joan (1985). Morfologia. Barcelona: Enciclopèdia Catalana.

McCarthy, John J. (2001). «Optimal Paradigms». University of Massachusetts, Amherst, manuscript. [Available on Rutgers Optimality Archive \#485, http://roa.rutgers.edu/. Slightly revised version published in Downing et al. 2005, pp. 170-210.]

McCarthy, John J.; Prince, Alan (1993). «Prosodic Morphology I: Constraint Interaction and Satisfaction». Report no. RuCCS-TR-3. New Brunswick, NJ: Rutgers University Center for Cognitive Science. [Available on Rutgers Optimality Archive \#482, http://roa.rutgers.edu/.]

McCarthy, John J.; Prince, Alan (1995). «Faithfulness and Reduplicative Identity». In: Beckman, Jill; Walsh Dickey, Laura; Urbanczyk, Suzanne (eds.). University of Massachusetts Occasional Papers in Linguistics 18: Papers in Optimality Theory. Amherst, MA: Graduate Linguistic Student Association, pp. 249-384. [Available on Rutgers Optimality Archive \#60, http://roa.rutgers.edu/.]

Orgun, Cemil Orhan; Sprouse, Ronald L. (1999). «From MPARSE to CONTROL: Deriving Ungrammaticality». Phonology 16: 191-224.

Prince, Alan S.; Smolensky, Paul (1993). «Optimality Theory. Constraint Interaction in Generative Grammar». Report no. RuCCS-TR-2. New Brunswick, NJ: Rutgers University Center for Cognitive Science. [2002 version available on Rutgers Optimality Archive \#537, http://roa.rutgers.edu/. Slightly revised version published in 2004 by Blackwell.]

Prince, Alan; Tesar, Bruce (2004). «Learning Phonotactic Distributions». In: Kager, René; Pater, Joe; Zonneveld, Wim (eds.). Fixing Priorities: Constraints in Phonological Acquisition. Cambridge: Cambridge University Press, pp. 245-291. [Available on Rutgers Optimality Archive \#353, http://roa.rutgers.edu/.]

Rice, Curt (2003). «Dialectal Variation in Norwegian Imperatives». Nordlyd 31: 372384. [Available at http://www.ub.uit.no/munin/nordlyd/. Prepublication version available on Rutgers Optimality Archive \#642, http://roa.rutgers.edu/.]

Steriade, Donca (2000). «Paradigm Uniformity and the Phonetics-Phonology Boundary». In: Broe, Michael B.; Pierrehumbert, Janet (eds.). Papers in Laboratory Phonology, V. Acquisition and the Lexicon. Cambridge: Cambridge University Press, pp. 313-334. Stump, Gregory T. (1991). «A Paradigm-based Theory of Morphosemantic Mismatches». Language 67: 675-725.

Stump, Gregory T. (1997). «'Template’ Morphology and Inflectional Morphology». In: Boojt, Geert; van Marle, Jaap (eds.). Yearbook of Morphology 1996. Dordrecht: Kluwer, pp. 217- 241.

van Marle, Jaap (1985). On the Paradigmatic Dimension of Morphological Creativity. Dordrecht: Foris.

van Marle, Jaap (1994). «Paradigms». In: Asher, Ronald E.; Simpson, John M. Y. (eds.). The Encyclopedia of Language and Linguistics, vol. VI. Oxford: Pergamon, pp. 2927-2930. 
Wheeler, Max W. (2002). «Flexió verbal irregular i verbs defectius». In: Solà, Joan; Lloret, Maria-Rosa; Mascaró, Joan; Pérez Saldanya, Manuel (eds.). Gramàtica del català contemporani, vol. I. Barcelona: Empúries, pp. 649-729

Wurzel, Wolfgang Ulrich (1989). Inflectional Morphology and Naturalness. Dordrecht: Kluwer. [English translation of Flexionsmorphologie und Natürlichkeit. Ein Beitrag zur morphologischen Theoriebildung. Berlin: Akademie Verlag, 1984.] 